\begin{tabular}{|c|c|}
\hline Title & Degrees and dollars: Health costs associated with suboptimal ambient temperature exposure \\
\hline Author(s) & Liu, Y ang; Saha, Shubhayu; Hoppe, Brendalynn O.; Convertino, Matteo \\
\hline Citation & $\begin{array}{l}\text { Science of the total environment, } 678,702-711 \\
\text { https://doi.org/10.1016/.scitotenv.2019.04.398 }\end{array}$ \\
\hline Issue Date & $2019-08-15$ \\
\hline Doc URL & http://hdl .handle.net/2115/82451 \\
\hline Rights & $\begin{array}{l}\text { () 2019. This manuscript version is made available under the CC-BY-NC-ND } 4.0 \text { license } \\
\text { http://reativecommons.org/icenses/by-nc-nd/4.0/ }\end{array}$ \\
\hline Rights(URL) & https:/creativecommons.org/icenses/by-nc-nd/4.0/ \\
\hline Type & article (author version) \\
\hline Additional Information & There are other files related to this item in HUSCAP. Check the above URL. \\
\hline File Information & main_STOTEN_nc.pdf \\
\hline
\end{tabular}

Instructions for use 


\section{Degrees and Dollars - Health Costs Associated with Suboptimal \\ 2 Ambient Temperature Exposure}

3

4

$5 \quad$ Yang Liu

6 London School Of Hygiene And Tropical Medicine

7

8 Brenda Hoppe

9 MN Department of Health

10

11 Saha Shubhayu

$12 \mathrm{CDC}$

13

14 Matteo Convertino

15 Nexus Group, Graduate School of Information Science and Technology, \& GI-CoRE for Big-Data 16 and Cybersecurity, Hokkaido University, Sapporo, JP

17

18 Abstract

19 Suboptimal ambient temperature exposure significantly affects public health. Previous studies have

20 primarily focused on risk assessment, with few examining the health outcomes from an economic

21 perspective. To inform environmental health policies, we estimated the economic costs of health

22 outcomes associated with suboptimal temperature in the Minneapolis/St. Paul Twin Cities

23 Metropolitan Area.

24 We used a distributed lag nonlinear model to estimate attributable fractions/ cases for mortality,

25 emergency department visits, and emergency hospitalizations at various suboptimal temperature

26 levels. The analyses were stratified by age group (i.e., youth (0-19 years), adult (20-64 years), and 
27 senior $(65+$ years $))$. We considered both direct medical costs and loss of productivity during

28 economic cost assessment.

29 Results show that youth have a large number of temperature-related emergency department visits,

30 while seniors have large numbers of temperature-related mortality and emergency hospitalizations.

31 Exposures to extremely low and high temperatures lead to $\$ 2.70$ billion [ $95 \%$ empirical confidence

32 interval (eCI): $\$ 1.91$ billion, $\$ 3.48$ billion] (costs are all based on 2016 USD value, $\$ 2016$ ) economic

33 costs annually. Moderately and extremely low and high temperature leads to $\$ 9.40$ billion [ $\$ 6.05$

34 billion, $\$ 12.57$ billion] economic costs. The majority of the economic costs are consistently

35 attributed to cold $(>75 \%)$, rather than heat exposures and to mortality $(>95 \%)$, rather than

36 morbidity. Our findings support prioritizing temperature-related health interventions designed to

37 minimize the economic costs by targeting seniors and to reduce attributable cases by targeting youth.

38

39 Keywords: climate health, climate change, extreme temperature, extreme heat, ambient exposure,

40 urban health 


\section{Introduction}

42 Ambient temperature exposures are associated with substantial adverse health impacts involving a

43 wide range of health conditions (Analitis et al., 2008; Basu, 2009; Chen et al., 2016; Ye et al., 2011).

44 As temperature is predicted to be more variable and extreme in the future (EPA, 2016), such health

45 risks are particularly concerning (Crimmins et al., 2016). Estimates from 2006-2010 show that 1,300

46 and 670 premature deaths are related to extreme cold and heat exposure, respectively, in the United

47 States each year (Berko, Ingram, Saha, \& Parker, 2014). However, these estimates are based only on

48 clinical diagnoses of temperature-related illnesses such as hypothermia and hyperthermia and known

49 to underestimate the true burden by omitting cases where ambient temperature was a contributing

50 exposure (Crimmins et al., 2016). Decision makers tasked with protecting communities from

51 environmental hazards like extreme temperatures not only need better assessments of the number of

52 individuals impacted, but the associated economic burden as well. The latter is critical as decision

53 makers attempt to allocate resources and justify budgets for environmental health planning across a

54 range of environmental hazards (e.g., air pollution) that impact communities besides extreme

55 temperature (Hutton \& Menne, 2014).

Although the relationship between ambient temperature and population health is well

57 studied, few investigators have linked health risks to economic costs. Knowlton et al. (2011), Lin et

58 al. (2012), and Schmeltz et al. (2016) are among the few that have provided such economic

59 estimates. However, the information provided in these studies is limited, as they consider only a few

60 health outcomes for limited periods in the year. For instance, Knowlton et al. (2011) analyzed a

61 specific two-week long heat wave in California during summer 2006, despite evidence that

62 temperature-related adverse health impacts occur year-round and with considerable seasonal

63 variability (Gasparrini et al., 2015, 2016). Lin et al. (2012) and Schmeltz et al. (2016) only considered 
64 hospitalizations, despite evidence that temperature impacts a wider range of health outcomes (e.g., 65 mortality (Gasparrini et al., 2015) and emergency department visits (Saha, Brock, Vaidyanathan,

66 Easterling, \& Luber, 2015; Zhang et al., 2014)). Failing to account for multiple outcomes leads to

67 underestimation of the corresponding economic burdens. These studies also provide insufficient

68 information on how the health and economic burden change over a larger range of temperature,

69 limiting the integration of temperature and health response functions into health intervention 70 planning.

72 economic burden associated with exposure to a range of cold and hot temperatures in the

73 Minneapolis-St. Paul Twin Cities Metropolitan Area (TCMA). We include mortality, emergency

74 department visits, and emergency hospitalizations in this analysis. The economic costs estimated 75 account for direct medical costs and productivity loss.

\section{$76 \quad$ Data \& Methods}

\section{Public Health Data}

78 The Twin Cities Metropolitan Area includes seven counties (Anoka, Carver, Dakota, Hennepin,

79 Ramsey, Scott, and Washington) and has total residents of over 3 million (Minnesota Department of

80 Health, 2015). We obtained all-cause mortality (MORT) data (1998-2014) for these seven counties

81 from the Office of Vital Records, Minnesota Department of Health. All-cause morbidity data (2005-

82 2014) were collected from all emergency departments within the Minnesota Hospital Association

83 (MHA) network, available from the Minnesota Hospital Discharge Dataset (MNHDD). The

84 MNHDD contains patient claims data voluntarily submitted by members of the MHA, a trade

85 association representing Minnesota Hospitals. The Minnesota Department of Health (MDH)

86 purchases these data from MHA under a Memorandum of Understanding between MHA and 
$87 \mathrm{MDH}$. The morbidity dataset further breaks down to emergency department visits followed by

88 discharge (EDV) and emergency department visits followed by hospitalization (EDHSP). For this

89 analysis, we assume that patients do not stay for treatment in an emergency department for longer

90 than three days without being hospitalized, as emergency departments normally cannot

91 accommodate extended stays. Consequently, we removed 11,138 EDV records (approximately $0.2 \%$

92 of total morbidity records) with emergency department stays longer than three days. We stratified

93 the data further by age: youth (0-19 years), adult (20-64 years), and senior (65+ years).

94 Environmental Data

95 We extracted historical hourly meteorological data for the TCMA for seven National

96 Weather Service weather stations within the TCMA on both raw data (i.e. air temperature) and

97 compound temperature indicators (i.e. heat index, wind chill index, and wet bulb global

98 temperature). We use daily maximum heat index $\left(\mathrm{HI}_{\max }\right)$ as the ambient temperature metric, which is

99 calculated using air temperature $\left({ }^{\circ} \mathrm{F}\right)$ and relative humidity $(\%)$ according to the method of Rothfusz

100 (1990) for consistency with National Weather Service standards. This choice is based on

101 composition, current policy in use, time-at-exposure (e.g. few individuals are exposed when

102 minimum temperature is observed), and extensive model comparison (using different temperature

103 variables mentioned above and different statistics including daily minimum, mean, and maximum).

104 Outside of summer months, the values of $\mathrm{HI}_{\max }$ are comparable to daily maximum air temperature

105 in the TCMA. We assumed that all individuals within the TCMA had the same exposure level at any

106 given time during the study.

107 Although not selected for the final model, we considered air pollutants during the model

108 development phase. We obtained data on ozone $\left(\mathrm{O}_{3}\right)$ and particulates with diameters equal to or 109 smaller than 2.5 micrometers $\left(\mathrm{PM}_{2.5}\right)$ from the Minnesota Pollution Control Agency for the years 
2000 to 2010. More details on the exploratory analysis using air pollution as a potential confounder

111 are in Supplemental Information Section 1.

\section{Estimating the Exposure-Response Functions}

113 We used a DLNM to characterize the exposure-response function between temperature and

114 population health (Gasparrini et al. 2010). This method is appropriate because there are distinct

115 temporal delays (lag $\emptyset$ between the exposures and responses considered in this study (Anderson \&

116 Bell, 2009). Furthermore, this study used a quasi-Poisson generalized linear model:

$$
\ln \left(E\left(Y_{t}\right)\right)=\beta_{0}+c b+n s(\text { Date }, d f)+\beta_{1} \cdot \text { dow }+\underbrace{\beta_{2} \cdot \text { holidays }}_{\text {Morbidity Models Only }}
$$

where $Y_{t}$ is the daily counts of public health outcomes; $c b$ is a cross-basis function that captures both the exposure-response relationship (i.e., how different exposure levels affect human health at a given

121 time) and the lag-response relationship (i.e., how a given exposure level affects human health at

122 different time lags). We further adjusted for day of week (dow), a long term trend (date), holiday

123 effects (holidays, only for morbidity model based on the results of likelihood ratio tests). More

124 specifically, this model assumes that exposure response relationship to be a natural cubic spline with

125 three internal knots at $10^{\text {th }}, 75^{\text {th }}, 90^{\text {th }}$ percentiles of the $\mathrm{HI}_{\max }$ distribution. The lag-response

126 relationship is also assumed to be a natural cubic spline function. Three internal knots are equally

127 spaced through the logarithmic lag range. The maximum lag considered is 28 days in order to

128 capture the delayed effects of cold exposure (Anderson \& Bell, 2009). The long-term trend is

129 assumed to be a natural cubic spline function with 8 and 7 degrees of freedom given to each year for

130 the mortality and morbidity models, respectively. Holiday effect is only significant for morbidity

131 outcomes and is adjusted for by including a binary variable that equals 1 on federal holidays and 3 
132 following days and 0 on other days. These model specifications are based on extensive mode

133 comparisons using quasi-Akaike Information Criterion and Mean Absolute Errors. More details on

134 model selection can be found in the Supplemental Information Section 2.

135 We calculate all risk estimates relative to reference baselines that correspond to minimum relative 136 risk (RR) (Tobías, Armstrong, \& Gasparrini, 2017). This baseline is referred to as the minimum

137 effect temperature (MET) in this study for both mortality and morbidity outcomes. For RR

138 estimates, statistical significance is defined as the probability of type I error is smaller than 0.05 .

\section{Attributable Fraction and Attributable Cases}

140 We calculate attributable fractions (AF) and attributable cases (AC) to show the percentage and

141 number of cases of the health outcomes associated with hazardous ambient temperature exposures.

142 To calculate AFs and ACs, we used a method in Gasparrini and Leone (2014). The underlying

143 assumption is a backward perspective - the health response at a given time $t$ is a result of many

144 exposure events that led up to it. More specifically, AF and AC are defined as:

$$
A F_{x, t}=1-\exp \left(-\sum_{l=0}^{L} \beta_{x_{t-l}, l}\right)
$$

$$
A C_{x, t}=A F_{x, t} \cdot Y_{t}
$$

147 where $x$ is the ambient temperature exposure level at time $t ; \beta x_{t-l, l}$ is the natural logarithm of RR

148 given exposure at time $t-l\left(\right.$ i.e., $\left.\chi_{t-1}\right)$ after $l$ days have elapsed; $N_{t}$ is daily counts of population health

149 outcomes at time $t$. In this study, we examined attributable risks for two temperature ranges:

150 moderate to extreme exposures, defined by the bottom and top 30\% of the historical temperature

151 record $\left(40\right.$ and $76^{\circ} \mathrm{F}$, respectively); and extreme exposures, defined by the bottom and top $5 \%$ of the

152 historical temperature records $\left(18\right.$ and $89^{\circ} \mathrm{F}$, respectively). Exposure ranges are defined by percentiles

153 as opposed to absolute temperature values to sure our results are interpretable in different urban 
154 climate settings. The over-arching goal is to compare the health outcomes and relevant economic

155 burdens attributable to different levels of cold and heat exposures. We examined both AF and AC

156 to identify the most vulnerable and the most affected age groups.

157 When it comes to uncertainty assessment for AF and AC, it is challenging to obtain an analytical 158 solution using the approach in Gasparrini and Leone (2014) (Graubard and Fears 2005). Therefore, 159 Monte Carlo simulations $(n=5,000)$ were used to express uncertainty as $95 \%$ empirical confidence 160 intervals (eCI).

161 Year-to-Year Variations for Cost Estimation

162 Various parameters for estimating costs, such as Cost-to-Charge Ratios (CCR), differ drastically 163 from year to year. Consequently, there is a need to explore the year-to-year variability in terms of 164 AC. This study proposes an incremental approach:

$$
A C(y)_{p}=\left\{\begin{array}{cc}
\sum_{i=1}^{m_{y}} A C_{x, t_{i}}, & y=1 \\
\sum_{i=1}^{m_{y}} A C_{x, t_{i}}-\sum_{i=1}^{m_{y-1}} A C_{x, t_{i}}, & y>1
\end{array}\right.
$$

where $A C(y)_{p}$ denotes the point estimation of AC during year $y ; m_{y}$ is the number of observations in

167 the first $y$ years of the time series. The uncertainty around $A C(y)_{p}$ is assumed to depend on that of $168 A C(y)_{\text {p.tot }}$ In other words, for each simulation result of total attributable cases $\left(A C_{\text {tot.sim }}\right)$ there is an 169 annual attributable cases $\left(A C_{\text {sim }}\right)$ defined as:

$$
A C(y)_{\text {sim }}=\frac{A C(y)_{p}}{A C_{\text {tot. }}} A C_{\text {tot.sim }}
$$

171 The results of this intermediate step are shown in Supplemental Information Section 3.

\section{Cost estimation}

We use the Value of a Statistical Life (VSL) to estimate the total health-related costs of

175 mortality. VSL is the "societal willingness to pay for mortality risk reductions" (Kenkel, 2003) and is 
176 independent of any health, demographic, or socioeconomic characteristics. The economic loss due

177 to mortality is the product of total lives lost and VSL. We convert the mean VSL estimate of $\$ 4.8$

178 million (\$1990) (U.S. EPA, 1997), which is based on a 1997 meta-analysis, to 2016 dollars (details in

179 Supplemental Information sections 4.1.1-4.1.3). We also considered several updated VSL estimates

180 (Thomson \& Monje, 2015), ranging from \$5.56 to \$13.90 million (\$2016) (Supplemental

181 Information Section 4.1.4). All cost parameters and estimates in this study are in $\$ 2016$, unless

182 otherwise specified.

Medical cost of temperature-related morbidity depend on the number of EDVs and

184 EDHSPs that are associated with temperature exposure and the loss in productivity for extended

185 stay at the healthcare facility. To estimate the population level medical cost, we used three factors:

186 total billed charges reflected on individual emergency department records or discharge forms, cost-

187 to-charge ratio (CCR), and the professional fee ratio (PFR). CCR converts the total amount billed to

188 an amount that approximates what the medical facility receives (Levit, Friedman, \& Wong, 2013). In

189 this study, total billed charges and CCR were calculated from emergency department records in the

190 TCMA and differs from year to year. PFR accounts for costs that are not facility-based, such as

191 salaries for physicians and other healthcare professionals. This study used the PFR value for EDV

192 among commercially insured individuals, 1.286, estimated by Peterson et al. (2015). Notably, PFR

193 estimates for EDHSP or for Medicaid visits do not vary substantially for other insurance types,

194 based on the same study.

We used the Daily Production Value (DPV) to calculate the productivity loss for the days

196 when individuals were at the healthcare facility as a result of EDV or EDHSP. Grosse et al. (2009)

197 provided the DPV estimates for 5-year age groups starting from 15-19 years using a combination of

198 factors such as average daily working hours, usual hourly compensation, daily market compensation 
199

200

201

202

203

204

205

206

207

208

209

210

\section{Results}

212 Descriptive statistics of the study population are in Table 1. Between 1998 and 2014, there were

$$
\begin{aligned}
\text { Morbidity Cost }= & \text { Medical Cost }+ \text { Productivity Loss } \\
= & \text { Attributable EDV or EDHSP } \times \\
& (\text { Total Billed Charges } \times \text { CCR } \times \text { PFR }+ \text { Length of Stay } \times \text { DPV })
\end{aligned}
$$

Research involving the collection or study of existing data and if the information is recorded by the investigator in such a manner that subjects cannot be identified, directly or through identifiers link to the subjects, is exempt from the International Review Board approval at the Minnesota Department of Health. 301,198 deaths in the TCMA, with a majority being seniors (65+ years). The morbidity dataset

214 contains 8,117,358 records with a majority being adults (20-64 years). Among them, 17.9\%

$215(1,447,793)$ were EDHSPs with an average hospital stay of 4.42 days.

217 mortality and morbidity. These functions characterize the relative risk associated with each

218 temperature exposure level compared to the reference level (i.e., MET). In the total population 
219 (Figure $1(\mathrm{a})$ ), $\mathrm{MET}$ is $84^{\circ} \mathrm{F}$ for mortality and $71^{\circ} \mathrm{F}$ for EDV and EDHSP. (MET estimates in Figure 220 1(b-d) are shown in Supplemental Information Section 5). As expected, the U- or J-shapes of the 221 exposure-response functions show low health risk at moderate exposure levels. High temperatures 222 are associated with increased risk for mortality and EDV but not for EDHSP. Low temperatures are 223 associated with increased risk across all population health outcomes. Age-specific analyses reveal 224 three additional pieces of information that are important for understanding the relationship between 225 temperature and population health. First, ambient temperature exposure is associated with mortality 226 in the oldest age group (65+ years) only. Based on our results, ambient temperature exposure is not 227 associated with mortality in the two younger age groups. Thus, we do not provide the relevant 228 mortality burdens for them. Second, based on measures of morbidity, extreme heat exposures only 229 affect youth (Figure 1(b-d)). Third, moderate and extreme cold affects morbidity in all age groups. 230 Uncertainty around RR estimated here are further captured by ACs, discussed below and in 231 Supplemental Information Section 6, computed via the Monte Carlo simulation process mentioned 232 above (Gasparrini and Leone 2014). Figures 2 and 3 show AFs and ACs across exposure types (cold and heat) and magnitudes

234 (moderate to extreme exposures and extreme exposures only) by age group. Mortality results, 235 marked in red, are only shown for seniors (65+ years). From 1998 to 2014, inclusive, 13,991 (6.2\%) 236 deaths among seniors are attributed to moderate to extreme cold exposures and 3,444 (1.5\%) to 237 extreme cold exposures. During the same period and in the same age group, 2,016 (0.9\%) deaths are 238 attributed to moderate to extreme heat exposures and 1,144 (0.5\%) to extreme heat exposures.

We analyzed EDV and EDHSP results in the same way. Youth (0-19 years) is the only age 240 group with substantial health burden associated with heat exposures. There are 23,478 [95\% eCI:

$2418,751,37,860](1.2 \%$ [95\% eCI: 0.4\%, 1.9\%]) cases of EDVs and 1,089 [95\% eCI: 194, 1,929] (0.78\% 
242 [95\% eCI: 0.1\%, 1.4\%]) EDHSPs associated with moderate to extreme heat exposures. Among

243 them, 12,079 [95\% eCI: 7,512, 16,420] (0.6\% [95\% eCI: 0.4\%, 0.8\%]) EDVs and 657 [95\% eCI: 102,

244 1,189] (0.5\% [95\% eCI: 0.1\%, 0.9\%]) EDHSPs are associated with extreme heat exposures. Heat

245 exposures are not associated with health burden among adults (20-64 years) or seniors (65+ years) in

246 the TCMA. Regarding cold, there are positive AFs and ACs for all health outcomes and for all age

247 groups considering moderate to extreme exposures. Given EDV, youth has the highest AF as well

248 as AC (7.03\% [95\% eCI: 5.9\%, 8.1\%], 137,622 [95\% eCI: 115,749, 157,331], respectively). However,

249 the EDHSP-specific analysis shows that although the youth has the highest AF $(6.6 \%$ [95\% eCI:

$2502.5 \%, 10.3 \%])$, seniors have the highest AC (24,252 [95\% eCI: 15,750, 32,327]). The underlying

251 reason is that there are many more senior EDHSPs than youth EDHSPs. When we considered only

252 extreme cold, all estimates become smaller, as expected, and the AF and AC among senior EDV

253 cases were no longer positive; otherwise, all patterns were similar to those described above. The

254 attributable EDHSPs for youth, adult, and senior are 2,488 [95\% eCI: 1,225, 3,680], 4,372 [95\% eCI:

$2551,992,6,732]$, and 4,445 [95\% eCI: 2,319, 6,509] - their differences become smaller than that

256 considering moderate to extreme cold exposures. Overall, youth is the most vulnerable but not

257 always the most affected (measured by burden) age group. Based on EDHSP AC, seniors and adults

258 are both have higher health burden compared to the youth. Numbers used to generate Figures 2 and 2593 are in Supplemental Information Section 6.

After taking into consideration inflation and income growth, based on total AC in the 65+

261 years age group and the VSL estimated by U.S. EPA (1997), the mortality costs related to moderate

262 to extreme cold and heat exposures are $\$ 8,119.33$ million [95\% eCI: $\$ 4,158.15$ million,

$263 \$ 11,862.49$ million] and $\$ 1,167.50$ million [95\% eCI: \$478.11 million, $\$ 1,839.77$ million] per year,

264 respectively. The mortality costs related to extreme cold and heat only are $\$ 2,00.67$ million [95\%

265 eCI: \$1,152.52 million, \$2,809.77 million] and \$665.06 million [95\% eCI: \$276.35, \$1,041.53 million] 
dollars per year, respectively. Using updated VSL values of Thomson and Monje (2015) did not lead to substantial changes in these estimates (Supplemental Information Section 4.1.5).

After taking into consideration inflation, the overall results show that the medical costs for EDHSP are higher than those of EDV due to the durations of stay. In addition, the medical costs due to cold exposures are higher than those of heat due to higher health burden (i.e. AC and AF). Among EDVs, the largest contributor to annual medical costs is the 0-19 years age group under cold exposure. This age group accounts for $\$ 8.18$ million [95\% eCI: $\$ 7.82$ million, $\$ 8.54$ million] in medical expenses associated with moderate to extreme cold exposures and $\$ 2.21$ million [95\% eCI: \$2.11 million, \$2.32 million] associated with only extreme cold exposures (Table 2 and 3). Among EDHSPs, the largest contributor to annual medical costs is the 65+ year age group under cold exposure, which accounted for $\$ 37.20$ million [95\% eCI: $\$ 33.48$ million, $\$ 40.85$ million] in medical expenses associated with moderate to extreme cold exposures and $\$ 6.85$ million [95\% eCI: $\$ 5.81$ million, $\$ 7.90$ million] associated with only extreme cold exposures.

Among adults (20-64 years), productivity loss was associated with relevant EDVs and EDHSPs under cold exposures. Considering moderate to extreme cold exposures among adults, the annual productivity loss is $\$ 1.63$ million [95\% eCI: $\$ 1.41$ million, $\$ 1.84$ million] due to EDVs and \$1.93 million [95\% eCI: \$1.64 million, \$2.22 million] due to EDHSPs. Considering extreme cold exposures only, the annual productivity loss is $\$ 0.29$ million [95\% eCI: $\$ 0.23$ million, $\$ 0.35$ million] due to EDVs and \$0.46 million [95\% eCI: \$0.38 million, \$0.55 million] due to EDHSPs.

Each year, the health burden associated with ambient temperature exposure leads to economic costs of approximately $\$ 9.40$ billion [95\% eCI: $\$ 6.05$ billion, $\$ 12.57$ billion] considering both moderate and extreme exposures and $\$ 2.70$ billion [95\% eCI: $\$ 1.91$ billion, $\$ 3.48$ billion] 
288

289

290

291

292

293

294

295

296

297

298

299

300

301

302

303

304

considering only extreme exposures in the TCMA. Morbidity loss makes up roughly $0.1-2.5 \%$ of the total costs depending exposure magnitude and age group.

\section{Discussion}

This study presents estimates of the health-related economic costs associated with ambient temperature exposures for the TCMA - approximately $\$ 9.40$ billion annually when both extreme and moderate exposures are considered. This comprehensive estimate relies on multiple criteria, capturing different population health outcomes. The World Health Organization recommends the use of such multi-criteria approach for estimating health-related costs associated with climate change as a means of internalizing an array of external costs, enabling comparison across different outcomes, and providing explicit rules for balancing a range of information (Hutton, Sanchez, \& Menne, 2013). Based on such multi-criteria approach, our results show that cold exposures are responsible for the economic costs for the TCMA considering mortality and emergency department visits. This holds true regardless of health outcome or age group. Harsh winters and freezing temperatures pose serious health risks even for a well-acclimatized population. The methods developed in this study demonstrate strengths that recommend its application for other jurisdictions and types of environmental exposures.

Our findings highlight that temperature-related costs vary by age. Seniors are the only age group for which extreme temperature conditions are associated with increased mortality. These results are broadly consistent with Hajat et al. (2014), Dang et al. (2016), and Yang, Ou, Ding, Zhou, \& Chen, (2012), which demonstrate that mortality associated with ambient temperature exposure is greater for persons 65 years or older compared to younger age groups. Consequently, the overall mortality costs are essentially mortality costs for seniors. Factors that make seniors more vulnerable to ambient temperature exposures include social isolation (Naughton et al., 2002), poverty (Basu \& 
312 Ostro, 2008), a high prevalence of chronic health conditions (Hajat et al., 2014), and reduced ability

313 to take preventive actions to mitigate exposures (Ebi, Mills, Smith, \& Grambsch, 2006). Regarding

314 morbidity outcomes, the relative risks for youth increase more rapidly than other age groups as

315 temperature move to the extremes of both cold and heat. Cold exposures affect all three age groups,

316 consistent with the results of Cui et al. (2016) and Zhang et al. (2014). The youth age group has the

317 highest AF associated with cold exposures. Heat exposures, on the other hand, affect only the

318 youth. Regarding this particular observation, current literature provides inconsistent evidence

319 (Nitschke et al. 2007, 2011; Kingsley et al. 2015; Zhang et al. 2014). It is important to keep in mind

320 that there are many more senior EDHSP cases than youth cases. Seniors hospitalized after

321 emergency department visits likely require more intensive and extensive medical services due to co-

322 morbidities and reduced physiological capacity (Ebi et al., 2006; Hajat et al., 2014). Therefore, it is

323 plausible that seniors contribute more to medical costs even though youth are associated with higher

324 health risks of EDHSP given hazardous temperature exposure.

This study suggests that studies that limit to seniors a priori, under the assumption that other

326 age groups are not as severely impacted by ambient temperatures, may be substantially

327 underestimating the total health burden. There are a large number of individuals 0-19 years whose

328 emergency department visits are also associated with ambient temperature although few of them

329 result in death. Therefore, this study confirms that the youngest and the oldest age groups both need

330 to be considered at risk (Sarofim et al., 2016; Xu et al., 2013). With regard to public health services,

331 focusing on both the youngest and the oldest individuals appears necessary. This analysis provides

332 information for supporting strategic prioritization of different age groups in intervention programs

333 (e.g., risk communication and education). Specific application will depend on the objective of the

334 decision maker. For instance, targeting youth is justifiable when the goal is to protect the most 
335 vulnerable individuals. Targeting seniors, especially when exposed to cold, may be more efficient in 336 reducing the overall economic costs.

The multi-criteria developed in this study is an extension of the theoretical framework in

338 Knowlton et al. (2011), with the goal of improving economic costs assessment of health risks

339 associated with ambient temperature exposure. This design accounts for various different aspects of

340 economic costs, such as medical expenses and productivity loss, simultaneous while considering a

341 single mortality or morbidity case. The overall economic costs can be considered a composite

342 indicator of impact measurement. This indicator allows for potential comparison between the public

343 health consequences of different environmental exposures, such as air pollution and extreme

344 temperature exposure, which involve multiple health outcomes and aspects of economic costs. The

345 capacity for comparison is crucial to public health decision makers with needs to prioritize at-risk

346 population and allocate scarce resources to manage different environmental exposures.

Although different public health outcomes are eventually summed to obtain the total

348 economic costs, it is easy to backtrack to the itemized cost criterion that contributes the most (or the

349 least) to the overall economic burden. For instance, in our study, we attribute $98 \%$ of the total

350 economic burden to mortality although the remaining $2 \%$ affects a much larger number of

351 individuals (see Supplemental Information Section 7). The theoretical framework of this study is

352 flexible. When new parameter estimates become available, cost estimates can be easily updated.

This study has a few limitations. With an ecological study design, the conclusions that we can

354 draw on the underlying causal mechanism are limited. The exposure measurement relies on

355 meteorological records. Future study may be able to utilize more advanced exposure measurement

356 technology to gain better insights into personal-level exposure intensity and duration. On mortality,

357 we assume VSL to be insensitive to age. This assumption is consistent with the current government 
practices (Thomson \& Monje, 2015; U.S. EPA NCEE, 2010). However, its validity and how VSL

359 vary with age are still up for debate among health economists (U.S. EPA NCEE, 2010) (Aldy \&

360 Viscusi, 2007). As for morbidity, we did not include some outcomes such as non-emergent clinical

361 visits due to data access. Such outcomes could be potentially relevant to sub-optimal cold exposure,

362 given the delayed effects. Future studies should consider further expanding morbidity measures.

363 This study considers only direct productivity losses. Indirect losses such as time off work that was

364 taken by parents who need to take care of their sick children are not included in the cost function,

365 which may result in underestimation. Regarding the overall cost function, it is important to point out

366 that by adding mortality costs and morbidity costs, theoretical costs (i.e., willingness-to-pay) are

367 added to transactions that have actually occurred (i.e., medical bills). To compensate for this

368 limitation, the itemized as well as the overall costs of public health burden associated with hazardous 369 ambient temperature exposures are both provided.

\section{Conclusion}

371

372 This study estimates economic costs incurred by the health burden of ambient temperature

373 exposures, a particularly relevant public health threat given the shifting temperature patterns due to

374 climate change. The results can help develop effective public health interventions that target specific

375 at-risk populations and inform resources allocation. Using multiple criteria to aggregate economic

376 estimates across different age groups leads to a useful, transparent, and flexible composite indicator

377 of costs. This approach can be adopted for assessing the overall impact of other environmental

378 exposures, such as air pollution, that involve multiple health outcomes and aspects of costs.

380 Funding Source: The research presented in this study is supported by the U.S. Centers for Disease 381 Control and Prevention, Grant Number: 5H13EH001125-03. 
383 Acknowledgments: The authors appreciate the generous support from the National Weather 384 Service (Chanhassen, Minnesota Forecast Office) and the Minnesota Pollution Control Agency in 385 acquiring the necessary data. 


\begin{tabular}{|c|c|}
\hline Abbreviation & Long Form \\
\hline CCR & Cost-to-charge ratio \\
\hline DPV & Daily production value \\
\hline DLNM & Distributed lag nonlinear model \\
\hline $\mathrm{eCI}$ & Empirical confidence interval \\
\hline EDHSP & Emergency department visits followed by hospitalization \\
\hline EDV & Emergency department visits followed by discharge \\
\hline EPA & Environmental Protection Agency \\
\hline $\mathrm{HI}$ & Heat index \\
\hline $\mathrm{MDH}$ & Minnesota Department of Health \\
\hline MET & Minimum effect temperature \\
\hline MM & Millions \\
\hline MORT & Mortality \\
\hline NWS & National Weather Service \\
\hline PFR & Professional-fee ratio \\
\hline RR & Relative risk \\
\hline TCMA & Minneapolis - St. Paul Twin Cities Metropolitan Area \\
\hline USD & U.S. dollar \\
\hline VSL & Value of a statistical life \\
\hline
\end{tabular}


Aldy, J. E., \& Viscusi, W. K. (2007). Age Differences in the Value of Statistical Life: Revealed Preference Evidence. Review of Environmental Economics and Policy, 1(2), 241-260. http://doi.org/10.1093/reep/rem014

Analitis, A., Katsouyanni, K., Biggeri, A., Baccini, M., Forsberg, B., Bisanti, L., .. Michelozzi, P. (2008). Effects of cold weather on mortality: Results from 15 European cities within the PHEWE project. American Journal of Epidemiology, 168(12), 1397-1408. http://doi.org/10.1093/aje/kwn266

Anderson, B. G., \& Bell, M. L. (2009). Weather-Related Mortality. Epidemiology, 20(2), 205-213. http://doi.org/10.1097/EDE.0b013e318190ee08

Basu, R. (2009). High ambient temperature and mortality: a review of epidemiologic studies from 2001 to 2008. Environmental Health, 8(1), 40. http://doi.org/10.1186/1476-069X-8-40

Basu, R., \& Ostro, B. D. (2008). A multicounty analysis identifying the populations vulnerable to mortality associated with high ambient temperature in California. American Journal of Epidemiology, 168(6), 632-637. http://doi.org/10.1093/aje/kwn170

Berko, J., Ingram, D. D., Saha, S., \& Parker, J. D. (2014). Deaths attributed to heat, cold, and other weather events in the United States, 2006-2010. National Health Statistics Reports, (76), 1-15. Retrieved from https://www.cdc.gov/nchs/data/nhsr/nhsr076.pdf

Chen, H., Wang, J., Li, Q., Yagouti, A., Lavigne, E., Foty, R., ... Copes, R. (2016). Assessment of the effect of cold and hot temperatures on mortality in Ontario, Canada: A population-based study. CMAJ Open, 4(1), E48-E58. http://doi.org/10.9778/cmajo.20150111

Crimmins, A., Balbus, J., Gamble, J. L., Beard, C. B., Bell, J. E., Dodgen, D., ... Eds. (2016). The Impacts of Climate Change on Human Health in the United States: A Scientific Assessment. In U.S. Global Change Research Program (p. 312). Washington, DC. http://doi.org/http://dx.doi.org/10.7930/J0R49NQX

Cui, Y., Yin, F., Deng, Y., Volinn, E., Chen, F., Ji, K., ... Li, X. (2016). Heat or cold: Which one exerts greater deleterious effects on health in a basin climate city? impact of ambient temperature on mortality in Chengdu, China. International Journal of Environmental Research and Public Health, 13(12). http://doi.org/10.3390/ijerph13121225

Dang, T. N., Seposo, X. T., Duc, N. H. C., Thang, T. B., An, D. D., Hang, L. T. M., ... Honda, Y. (2016). Characterizing the relationship between temperature and mortality in tropical and subtropical cities: A distributed lag non-linear model analysis in Hue, Viet Nam, 2009-2013. Global Health Action, 9(1). http://doi.org/10.3402/gha.v9.28738

Ebi, K. L., Mills, D. M., Smith, J. B., \& Grambsch, A. (2006). Climate change and human health impacts in the United States: An update on the results of the U.S. National Assessment. Environmental Health Perspectives, 114(9), 1318-1324. http://doi.org/10.1289/ehp.8880

Gasparrini, A., Guo, Y., Hashizume, M., Lavigne, E., Tobias, A., Zanobetti, A., ... Armstrong, B. G. (2016). Changes in Susceptibility to Heat During Summer: A Multicountry Analysis, 183(11), 18-20. http://doi.org/10.1093/aje/kwv260

Gasparrini, A., Guo, Y., Hashizume, M., Lavigne, E., Zanobetti, A., Schwartz, J., ... others. (2015). Mortality risk attributable to high and low ambient temperature: a multicountry observational study. The Lancet.

Gasparrini, A., \& Leone, M. (2014). Attributable risk from distributed lag models. BMC Medical Research Methodology, 14, 55. http://doi.org/10.1186/1471-2288-14-55 
Gasparrinia, A., Armstrong, B., \& Kenward, M. G. (2010). Distributed lag non-linear models. Statistics in Medicine, 29(21), 2224-2234. http:/ / doi.org/10.1002/sim.3940

Graubard, B. I., \& Fears, T. R. (2005). Standard errors for attributable risk for simple and complex sample designs. Biometrics, 61(3), 847-855. http://doi.org/10.1111/j.1541-0420.2005.00355.x

Grosse, S. D., Krueger, K. V, \& Mvundura, M. (2009). Economic productivity by age and sex: 2007 estimates for the United States. Medical Care, 47(7 Suppl 1), S94-S103. http://doi.org/10.1097/MLR.0b013e31819c9571

Hajat, S., Vardoulakis, S., Heaviside, C., \& Eggen, B. (2014). Climate change effects on human health: projections of temperature-related mortality for the UK during the 2020s, 2050s and 2080s. Journal of Epidemiology and Community Health, 1-8. http://doi.org/10.1136/jech-2013-202449

Hutton, G., \& Menne, B. (2014). Economic Evidence on the Health Impacts of Climate Change in Europe. Environmental Health Insights, 43. http://doi.org/10.4137/EHI.S16486

Hutton, G., Sanchez, G., \& Menne, B. (2013). Climate Change and Health : a tool to estimate health and adaption costs. Retrieved from http://www.euro.who.int/_data/assets/pdf_file/0018/190404/WHO_Content_Climate_change_heal th_DruckII.pdf

Kenkel, D. (2003). Using Estimates of the Value of a Statistical Life in Evaluating Consumer Policy Regulations. Journal of Consumer Policy.

Kingsley, S. L., Eliot, M. N., Gold, J., Vanderslice, R. R., \& Wellenius, G. A. (2015). Current and Projected Heat-Related Morbidity and Mortality in Rhode Island. Environmental Health Perspectives, 460(4), 1-8. http://doi.org/10.1289/ehp.1408826

Knowlton, K., Rotkin-Ellman, M., Geballe, L., Max, W., \& Solomon, G. M. (2011). Six climate change-related events in the United States accounted for about $\$ 14$ billion in lost lives and health costs. Health Affairs, 30(11), 2167-2176. http://doi.org/10.1377/hlthaff.2011.0229

Levit, K. R., Friedman, B., \& Wong, H. S. (2013). Estimating Inpatient Hospital Prices from State Administrative Data and Hospital Financial Reports. Health Services Research, 48(5), n/a-n/a. http:/ / doi.org/10.1111/1475-6773.12065

Lin, S., Hsu, W. H., van Zutphen, A. R., Saha, S., Luber, G., \& Hwang, S. A. (2012). Excessive heat and respiratory hospitalizations in New York State: Estimating current and future public health burden related to climate change. Environmental Health Perspectives, 120(11), 1571-1577. http://doi.org/10.1289/ehp.1104728

Minnesota Department of Health. (2015). MINNESOTA CLIMATE AND HEALTH PROFILE REPORT 2015. Minneapolis. Retrieved from https://www.health.state.mn.us/communities/environment/climate/docs/mnprofile2015.pdf

Naughton, M. P., Henderson, A., Mirabelli, M. C., Kaiser, R., Wilhelm, J. L., Kieszak, S. M., ... McGeehin, M. A. (2002). Heat-related mortality during a 1999 heat wave in Chicago. American Journal of Preventive Medicine, 22(4), 221-227. http:/ / doi.org/10.1016/S0749-3797(02)00421-X

Nitschke, M., Tucker, G. R., \& Bi, P. (2007). Morbidity and mortality during heatwaves in metropolitain Adelaide. Medical Journal of Australia, 187(11/12), 662-665. http://doi.org/10.1017/CBO9781107415324.004

Nitschke, M., Tucker, G. R., Hansen, A. L., Williams, S., Zhang, Y., \& Bi, P. (2011). Impact of two recent extreme heat episodes on morbidity and mortality in Adelaide, South Australia: a case-series analysis. Environmental Health : A Global Access Science Source, 10, 42. http://doi.org/10.1186/1476-069X-10-42 
Peterson, C., Xu, L., Florence, C., Grosse, S. D., \& Annest, J. L. (2015). Professional Fee Ratios for US Hospital Discharge Data. Med Care, 53(10), 840-849. http://doi.org/10.1097/MLR.0000000000000410. Professional

Rothfusz, L. P., \& Headquarters, N. S. R. (1990). The heat index equation (or, more than you ever wanted to know about heat index). Fort Worth, Texas: National Oceanic and Atmospheric Administration, National Weather Service, Office of Meteorology. Fort Worth, TX. Retrieved from papers://c6bd9143-3623-4d4f-963f62942ed32f11/Paper/p395

Saha, S., Brock, J. W., Vaidyanathan, A., Easterling, D. R., \& Luber, G. (2015). Spatial variation in hyperthermia emergency department visits among those with employer-based insurance in the United States - a case-crossover analysis. Environmental Health, 14(1), 20. http://doi.org/10.1186/s12940-015$0005-z$

Sarofim, M. C., Saha, S., Hawkins, M. D., Mills, D. M., Hess, J., Horton, R. M., ... Juliana, A. St. (2016). The Impacts of Climate Change on Human Health in the United States: A Scientific Assessment. In Global Climate Change Impacts in the United States (pp. 44-68). Washington, DC. http://doi.org/http://dx.doi.org/10.7930/J0MG7MDX

Schmeltz, M. T., Petkova, E. P., \& Gamble, J. L. (2016). Economic burden of hospitalizations for heat-related illnesses in the United States, 2001???2010. International Journal of Environmental Research and Public Health, 13(9). http://doi.org/10.3390/ijerph13090894

Thomson, K., \& Monje, C. (2015). Guidance on Treatment of the Economic Value of a Statistical Life (VSL) in U.S. Department of Transportation Analyses - 2015 Adjustment. Washington, DC. Retrieved from https://cms.dot.gov/sites/dot.gov/files/docs/VSL2015_0.pdf

Tobías, A., Armstrong, B., \& Gasparrini, A. (2017). Investigating Uncertainty in the Minimum Mortality Temperature: Methods and Application to 52 Spanish Cities. Epidemiology, 28(1), 72-76. http://doi.org/10.1097/EDE.0000000000000567

U.S. EPA. (1997). The Benefits and Costs of the Clean Air Act, 1970 to 1990. Retrieved from https://www.epa.gov/sites/production/files/2015-06/documents/contsetc.pdf

U.S. EPA NCEE. (2010). Valuing Mortality Risk Reductions for Environmental Policy: A White Paper, 95.

Xu, Y., Dadvand, P., Barrera-Gomez, J., Sartini, C., Mari-Dell'Olmo, M., Borrell, C., ... Basagana, X. (2013). Differences on the effect of heat waves on mortality by sociodemographic and urban landscape characteristics. J Epidemiol Community Health, 67(6), 519-525. http://doi.org/10.1136/jech-2012-201899

Yang, J., Ou, C.-Q., Ding, Y., Zhou, Y.-X., \& Chen, P.-Y. (2012). Daily temperature and mortality: a study of distributed lag non-linear effect and effect modification in Guangzhou. Environmental Health, 11(1), 63. http://doi.org/10.1186/1476-069X-11-63

Ye, X., Wolff, R., Yu, W., Vaneckova, P., Pan, X., \& Tong, S. (2011). Ambient Temperature and Morbidity: A Review of Epidemiological Evidence. Environmental Health Perspectives, 120(1), 19-28. http://doi.org/10.1289/ehp.1003198

Zhang, Y., Yan, C., Kan, H., Cao, J., Peng, L., Xu, J., \& Wang, W. (2014). Effect of ambient temperature on emergency department visits in Shanghai, China: a time series study, 1-8. http://doi.org/10.1186/1476069X-13-100 


\begin{tabular}{|c|c|c|c|c|c|c|c|c|c|}
\hline \multirow{3}{*}{$\begin{array}{c}\text { Age Group } \\
\text { (yo) }\end{array}$} & \multirow{2}{*}{\multicolumn{3}{|c|}{$\begin{array}{c}\text { Mortality } \\
(1998-2014) \\
\text { MORT }\end{array}$}} & \multicolumn{6}{|c|}{$\begin{array}{l}\text { Morbidity } \\
(2005-2014)\end{array}$} \\
\hline & & & & \multicolumn{3}{|c|}{ EDV } & \multicolumn{3}{|c|}{ EDHSP } \\
\hline & tot & $\mu$ & $\delta$ & tot & $\mu$ & $\delta$ & tot & $\mu$ & $\delta$ \\
\hline $0-19$ & 7,034 & 1 & 1 & $1,957,692$ & 536 & 84 & 139,318 & 38 & 9 \\
\hline $20-64$ & 68,550 & 11 & 3 & $3,980,639$ & 1,090 & 127 & 721,132 & 197 & 22 \\
\hline $65+$ & 225,614 & 36 & 7 & 720,096 & 197 & 40 & 587,343 & 161 & 18 \\
\hline All & 301,198 & 48 & 8 & $6,658,427$ & 1,823 & 210 & $1,447,793$ & 396 & 36 \\
\hline
\end{tabular}

516 Table 1. Mortality and morbidity in the Minneapolis-St. Paul Twin Cities Metropolitan Area.

517 Three population health outcomes are Mortality; EDV - Emergency Department Visits; EDHSP -

518 Emergency Department Visits followed by hospital admission. tot sums the total number of cases

519 for each population health outcomes over the course of 17 years for mortality and 10 years for

520 morbidity. $\mu$ - daily mean case counts; $\delta$ - daily variability measured by standard deviation. 


\begin{tabular}{|c|c|c|c|c|}
\hline Health Outcome & Cost Criteria & $\begin{array}{l}\text { Age } \\
\text { Group }\end{array}$ & $\begin{array}{c}\text { Moderate-Extreme Cold } \\
\text { Exposure } \\
\text { HI_max }<30^{\text {th }} \text { percentile } \\
\text { Expected Value } \\
{[95 \% \text { eCI }]}\end{array}$ & $\begin{array}{c}\text { Moderate-Extreme Heat } \\
\text { Exposure } \\
\text { HI_max }>70^{\text {th }} \text { percentile } \\
\text { Expected Value } \\
{[95 \% \text { eCI }]}\end{array}$ \\
\hline \multirow{3}{*}{$\begin{array}{l}\text { Mortality } \\
\text { (MORT) }\end{array}$} & \multirow{3}{*}{-} & $0-19$ & --- & -- \\
\hline & & $20-64$ & -- & -- \\
\hline & & $65+$ & $\begin{array}{c}8,119.33 \\
{[4,158.15,11,862.49]}\end{array}$ & $\begin{array}{c}1,167.50 \\
{[478.11,1,839.77]}\end{array}$ \\
\hline \multirow{6}{*}{$\begin{array}{c}\text { Emergency } \\
\text { Department } \\
\text { Visit } \\
(\text { EDV })\end{array}$} & \multirow{3}{*}{ Medical Costs } & $0-19$ & $\begin{array}{c}8.18 \\
{[7.82,8.54]} \\
\end{array}$ & $\begin{array}{c}1.40 \\
{[1.15,1.65]} \\
\end{array}$ \\
\hline & & $20-64$ & $\begin{array}{c}7.17 \\
{[6.25,8.11]}\end{array}$ & --- \\
\hline & & $65+$ & $\begin{array}{c}2.54 \\
{[2.01,3.06]}\end{array}$ & --- \\
\hline & \multirow{3}{*}{$\begin{array}{l}\text { Productivity } \\
\text { Loss }\end{array}$} & $0-19$ & $\begin{array}{c}0.16 \\
{[0.15,0.16]} \\
\end{array}$ & $\begin{array}{c}0.03 \\
{[0.02,0.03]} \\
\end{array}$ \\
\hline & & $20-64$ & $\begin{array}{c}1.64 \\
{[1.43,1.85]}\end{array}$ & - \\
\hline & & $65+$ & $\begin{array}{c}0.12 \\
{[0.10,0.15]}\end{array}$ & --- \\
\hline \multirow{6}{*}{$\begin{array}{c}\text { Emergency } \\
\text { Hospitalization } \\
\text { (EDHSP) }\end{array}$} & \multirow{3}{*}{ Medical Costs } & $0-19$ & $\begin{array}{c}12.81 \\
{[10.63,14.98]} \\
\end{array}$ & $\begin{array}{c}1.51 \\
{[1.11,1.94]} \\
\end{array}$ \\
\hline & & $20-64$ & $\begin{array}{c}27.69 \\
{[23.53,31.81]} \\
\end{array}$ & --- \\
\hline & & $65+$ & $\begin{array}{c}37.20 \\
{[33.48,40.85]}\end{array}$ & --- \\
\hline & \multirow{3}{*}{$\begin{array}{c}\text { Productivity } \\
\text { Loss }\end{array}$} & $0-19$ & $\begin{array}{c}0.04 \\
{[0.03,0.05]}\end{array}$ & $\begin{array}{c}0.005 \\
{[0.004,0.006]}\end{array}$ \\
\hline & & $20-64$ & $\begin{array}{c}1.93 \\
{[1.63,2.21]}\end{array}$ & --- \\
\hline & & $65+$ & $\begin{array}{c}0.78 \\
{[0.71,0.86]} \\
\end{array}$ & --- \\
\hline Total & - & - & $\begin{array}{c}8215.18 \\
{[4,908.92,11,357.45]}\end{array}$ & $\begin{array}{c}1,171.47 \\
{[614.26,1749.07]}\end{array}$ \\
\hline
\end{tabular}

521

522 Table 2. Cost estimates for each health outcomes by age groups (in million USD, \$2016)

523 attributable to moderate to extreme ambient temperature exposure. 


\begin{tabular}{|c|c|c|c|c|}
\hline Health Outcome & Cost Group & $\begin{array}{l}\text { Age } \\
\text { Group }\end{array}$ & $\begin{array}{c}\text { Extreme Cold Exposure } \\
\text { HI_max }<5^{\text {th }} \text { percentile } \\
\text { (unit }=\$ \mathrm{MM}) \\
\text { Expected Value } \\
{[95 \% \mathrm{eCI}]}\end{array}$ & $\begin{array}{c}\text { Extreme Heat Exposure } \\
\text { HI_max }>95^{\text {th }} \\
\text { percentile } \\
\text { (unit }=\$ \mathrm{MM} \text { ) } \\
\\
\text { Expected Value } \\
{[95 \% \text { eCI }]} \\
\end{array}$ \\
\hline \multirow{3}{*}{$\begin{array}{l}\text { Mortality } \\
\text { (MORT) }\end{array}$} & \multirow{3}{*}{-} & $0-19$ & --- & --- \\
\hline & & $20-64$ & --- & --- \\
\hline & & $65+$ & $\begin{array}{c}2,005.67 \\
{[1,152.52,2,809.77]}\end{array}$ & $\begin{array}{c}665.06 \\
{[276.35,1,041.53]}\end{array}$ \\
\hline \multirow{6}{*}{$\begin{array}{c}\text { Emergency } \\
\text { Department Visit } \\
(\text { EDV })\end{array}$} & \multirow{3}{*}{ Medical Costs } & $0-19$ & $\begin{array}{c}2.21 \\
{[2.11,2.32]} \\
\end{array}$ & $\begin{array}{c}0.73 \\
{[0.65,0.81]} \\
\end{array}$ \\
\hline & & $20-64$ & $\begin{array}{c}1.27 \\
{[1.00,1.54]}\end{array}$ & --- \\
\hline & & $65+$ & --- & --- \\
\hline & \multirow{3}{*}{$\begin{array}{l}\text { Productivity } \\
\text { Loss }\end{array}$} & $0-19$ & $\begin{array}{c}0.04 \\
{[0.04,0.04]} \\
\end{array}$ & $\begin{array}{c}0.01 \\
{[0.01,0.02]}\end{array}$ \\
\hline & & $20-64$ & $\begin{array}{c}0.29 \\
{[0.23,0.35]} \\
\end{array}$ & -- \\
\hline & & $65+$ & --- & --- \\
\hline \multirow{6}{*}{$\begin{array}{c}\text { Emergency } \\
\text { Hospitalization } \\
(\mathrm{EDHSP})\end{array}$} & \multirow{3}{*}{ Medical Costs } & $0-19$ & $\begin{array}{c}3.49 \\
{[2.87,4.13]} \\
\end{array}$ & $\begin{array}{c}0.91 \\
{[0.63,1.22]} \\
\end{array}$ \\
\hline & & $20-64$ & $\begin{array}{c}6.57 \\
{[5.39,7.77]} \\
\end{array}$ & --- \\
\hline & & $65+$ & $\begin{array}{c}6.85 \\
{[5.81,7.90]} \\
\end{array}$ & --- \\
\hline & \multirow{3}{*}{$\begin{array}{l}\text { Productivity } \\
\text { Loss }\end{array}$} & $0-19$ & $\begin{array}{c}0.01 \\
{[0.01,0.01]} \\
\end{array}$ & $\begin{array}{c}0.003 \\
{[0.002,0.004]}\end{array}$ \\
\hline & & $20-64$ & $\begin{array}{c}0.46 \\
{[0.38,0.55]} \\
\end{array}$ & --- \\
\hline & & $65+$ & $\begin{array}{c}0.15 \\
{[0.12,0.16]} \\
\end{array}$ & --- \\
\hline Total & - & - & $\begin{array}{c}2,033.24 \\
{[1,318.64,2725.38]}\end{array}$ & $\begin{array}{c}6667.61 \\
{[343.46,993.11]} \\
\end{array}$ \\
\hline
\end{tabular}

524

525 Table 3. Cost estimates for each health outcomes by age groups (in million USD, \$2016)

526 attributable to extreme ambient temperature exposure. 

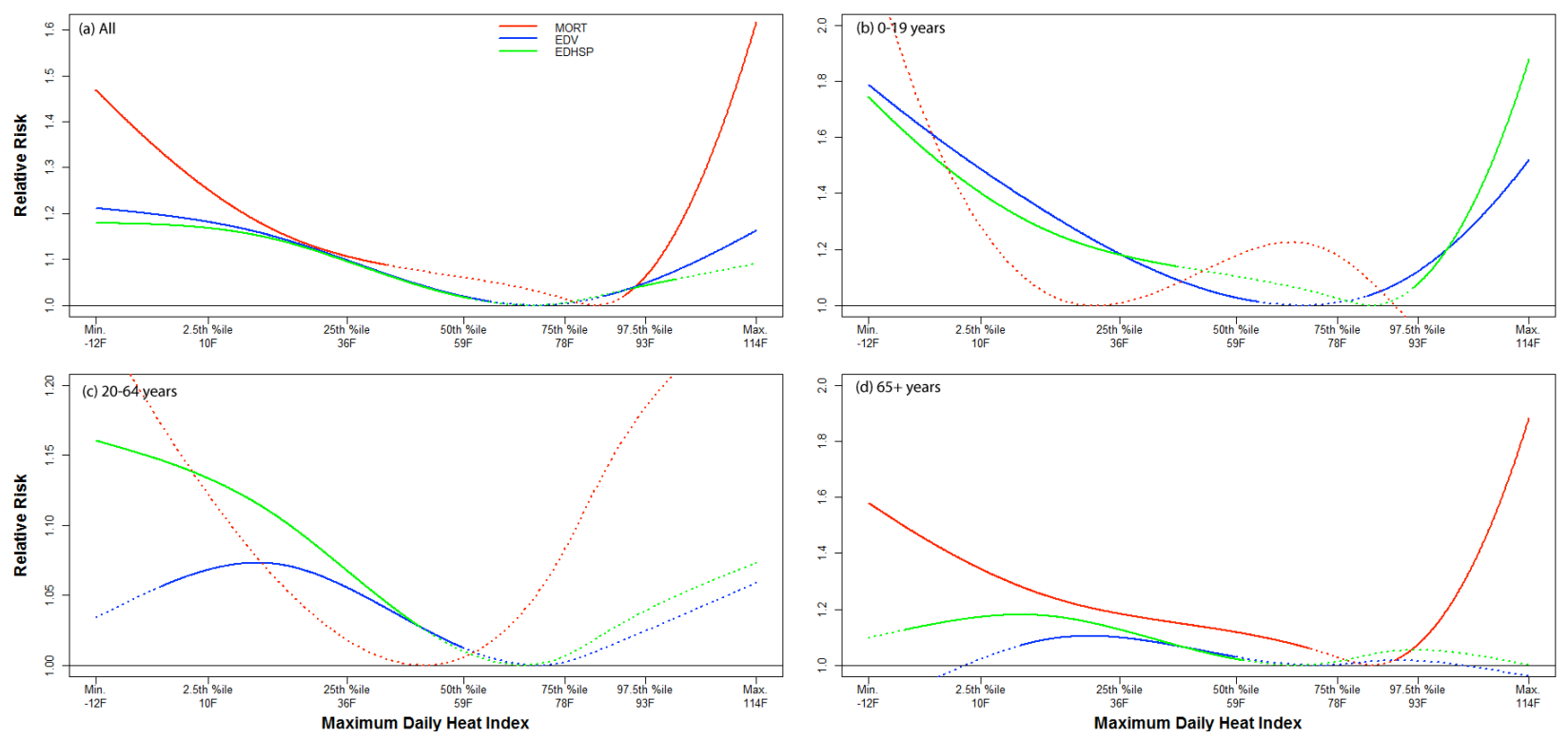

529 Figure 1. Exposure-response functions for each health outcome by age groups.

530 Solid lines indicate relative risks (compared to minimum effect temperature) significantly greater

531 than 1 ( $\mathrm{p}$-value $<0.05)$ and dotted lines indicate non-statistically significant results $(\mathrm{p}$-value $>=0.05)$.

532

533

534

535

536 


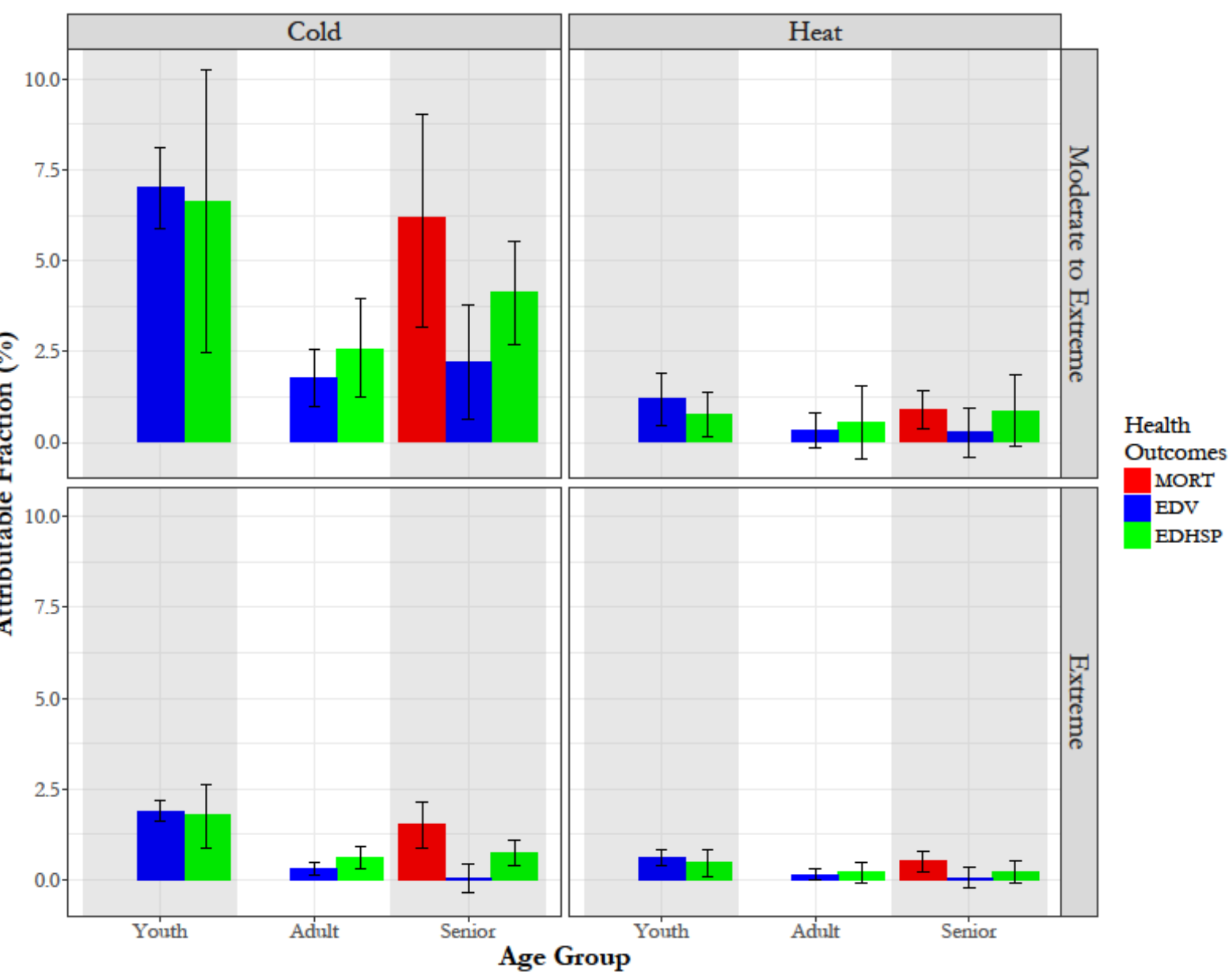

538 Figure 2. Attributable fraction of three health outcomes by age groups associated with temperature exposure.

540 The uncertainty range is defined by 95\% empirical confidence intervals obtained by Monte Carlo

541 simulations $(n=5000)$. This figure does not include mortality results regarding 0-19 year olds or 20-

54264 year olds because there is no increased relative risk of mortality at any exposure level for these 543 age groups. 


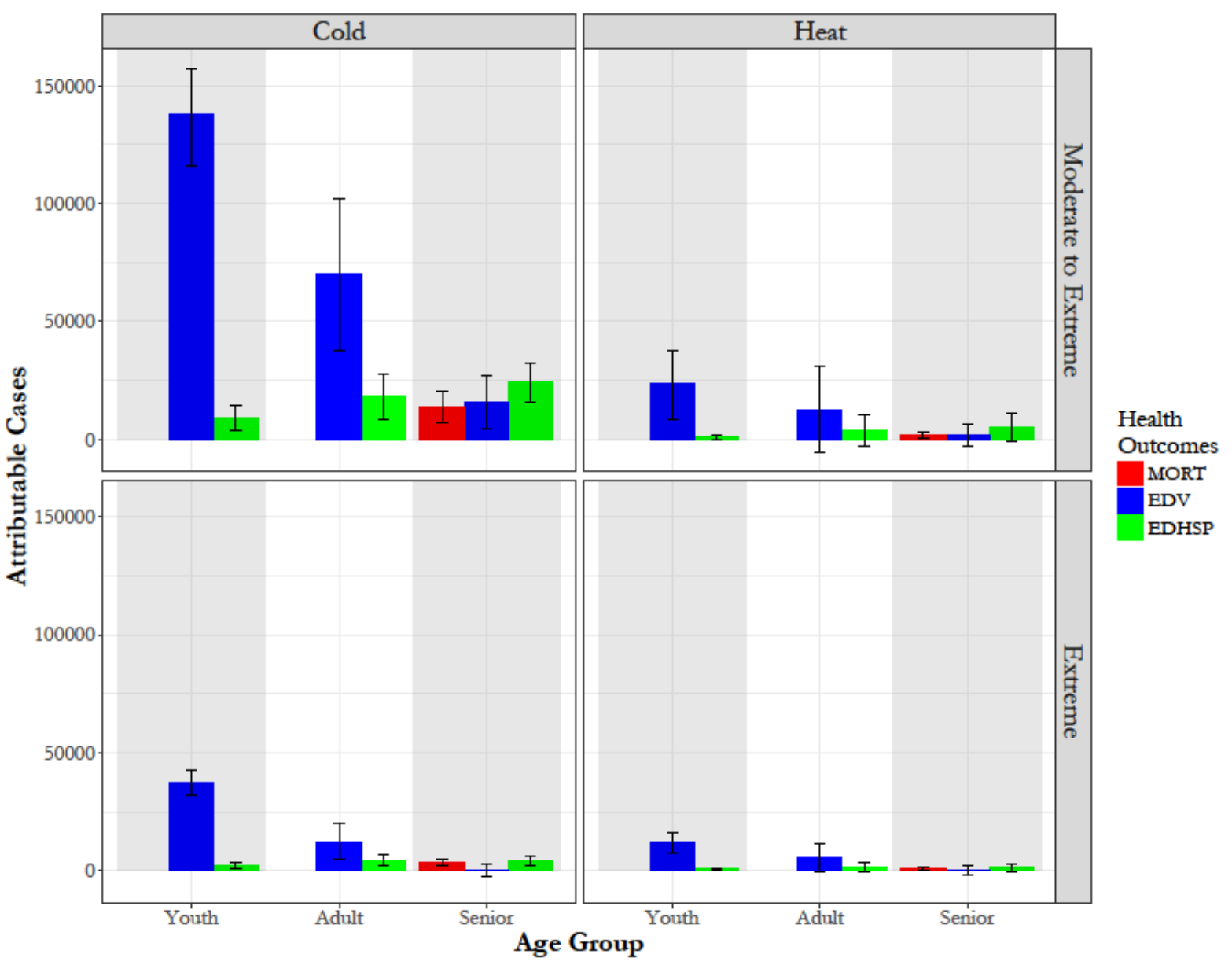

547 Figure 3. Attributable cases of three health outcomes by age groups associated with temperature 548 exposure.

549 The uncertainty range is defined by 95\% empirical confidence intervals obtained by Monte Carlo 550 simulations $(n=5000)$. This figure does not include mortality results regarding 0-19 year olds or 20-

55164 year olds because there is no increased relative risk of mortality at any exposure level for these 552 age groups. 